\title{
A consideration of the qualities of a 'good' doctor with some help from the humanities
}

It is a reasonable generalisation that most doctors aim to be skilled in the practice of medicine; they try to be 'good' doctors. Also, despite frequent news stories illustrating the shortcoming of doctors, surveys show that contemporary society holds the medical profession in high regard; ${ }^{1}$ doctors are generally considered to be 'good' people despite obvious exceptions such as Dr Harold Shipman.

But what do we mean by 'goodness' in medical practice? This essay uses sources from the arts and the humanities to explore this concept of 'goodness' and to consider the qualities of a 'good' doctor in a contemporary medical context.

Let us start with a consideration of a picture of a 'good' doctor. Van Gogh (1853-1890), produced several portraits

Doctor Gachet, Vincent Van Gogh, 1890.

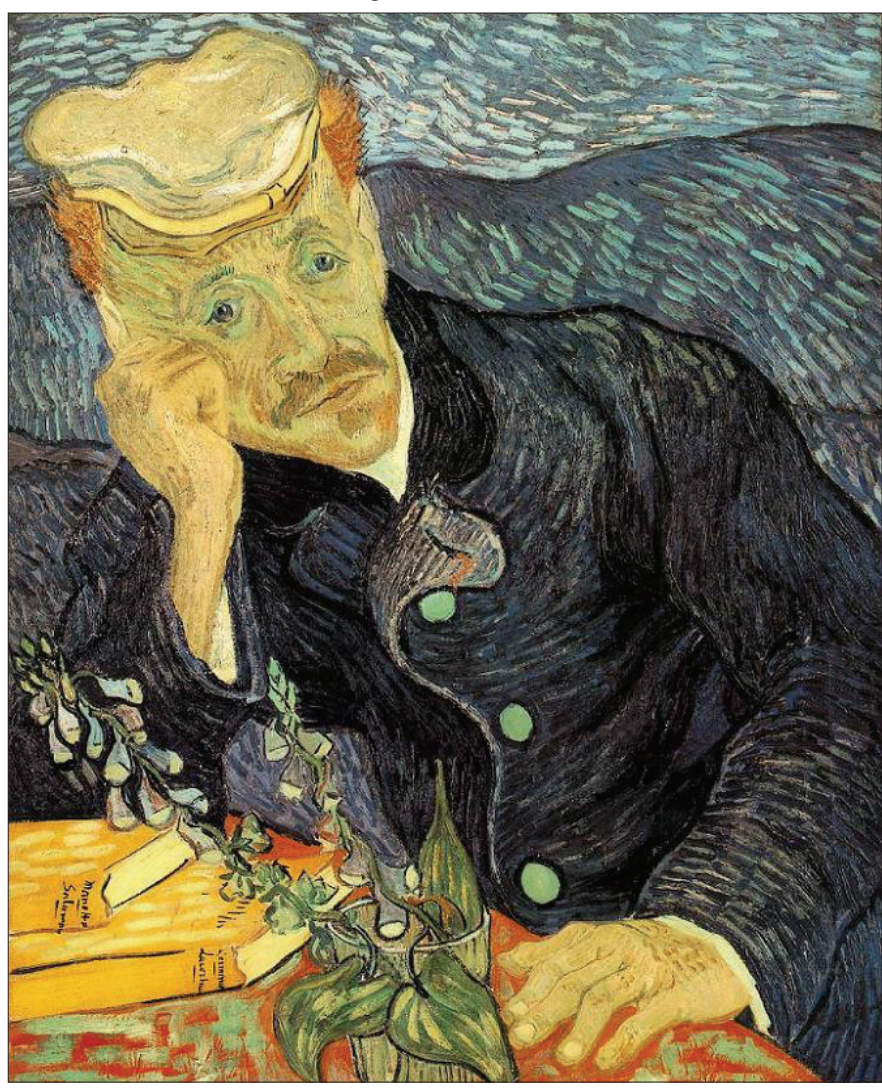

of his own physician, Dr Paul-Ferdinand Gachet. Van Gogh was a prolific artist, producing more than two thousand paintings, drawings, and sketches, also leaving detailed descriptions of his colourful life in letters and diaries. In a letter to his sister, Wilhemina Van Gogh, he wrote that in this painting he had tried to portray Gachet's 'sad but gentle, yet clear and intelligent' expression. ${ }^{2} \mathrm{~A}$ foxglove on the table represents Gachet's medical status and, possibly, the digitalis he prescribed for Van Gogh's mania. (It has been proposed that xanthopsia caused by digoxin poisoning explains Van Gogh's preoccupation with the colour yellow, though this seems unlikely.)

Van Gogh started painting in Belgium moving to Paris in 1886 where he met the impressionist artists Pissarro, Monet, and Gauguin. Although his paintings now sell for millions of pounds he failed to make any money in his own lifetime, his penury a constant preoccupation. He was a heavy drinker with a taste for absinthe and had bursts of manic activity followed by periods of depression. To improve his health he moved south to Arles to be joined by Gaugin. But, in a fit of mania or possible temporal lobe epilepsy, Van Gogh pursued his friend with an open razor and ended up cutting off a portion of his own earlobe. In 1890 after a stay in an asylum in Saint-Remy he went to live in Auvers-sur-Oise under the watchful eye of Dr Gachet. However, 2 months later he was dead, having shot himself. Gachet, himself an amateur painter, had been chosen to be Van Gogh's physician by his brother Théo. He hoped that Gachet's sensitivity toward artists would make him a 'good' doctor for Van Gogh's recurring bouts of mental illness. But was Gachet any help to Van Gogh? This extract is from a letter to Théo a month before he died:

'Now about Doctor Gachet ... first of all, he is sicker than I am, I think, or shall we say just as much, ... Now when one blind man leads another blind man, don't they both fall into the ditch?'3

Although there was not much available to any physician of the day which could have reversed the course of Van Gogh's illness, his suicide after just 10 weeks in Gachet's care has led to questioning and criticism of this 'good' doctor's role.

Attempts to define the concept of 'goodness' can be traced back to Aristotle (384-322 BC). His theory of 'virtue ethics' proposed that people with certain intrinsic good character traits make good decisions, and we should aspire to exhibit such qualities. Spicer ${ }^{4}$ considers the virtues that a modern healthcare professional should possess and lists determination, consistency, and a sense of humanity.' Altruism could be added to this list, although Jones writes that there is a growing feeling that altruism in medicine may be declining 'if not dying'. ${ }^{5}$ A moving account of a family doctor, Dr John Sassal, exploring the demands and rewards of medical virtue can be found in John Berger's book $A$ Fortunate Man. ${ }^{6}$ The book includes 
accounts of Sassal's battle with recurrent depression, a sad footnote being his suicide some years after the book was published.

The many philosophical and moral discourses with direct relevance to the concept of 'goodness' in the context of medical practice include Kant's 'moral imperatives' and Mills' 'utilitarianism'.? Kant (1724-1804), wrote that to be virtuous, we do our duty and ignore our own inclinations or judgements. For a doctor this may lead to conflict; consider the clash of a doctor's duty of care to a patient requesting termination of pregnancy and the Roman Catholic faith. John Stuart Mill (1806-1873), proposed that the rightness or wrongness of an action is determined only by the consequences, an action producing the greatest good being, by definition, the right action. However, the application of Mills' utilitarian principle can lead to difficulties for the 'good' doctor. Individual medical decisions may conflict with NHS provision as patients have to wait their turn or even be denied beneficial treatment when health care is based on assessment of the 'greater good' of a population. The contemporary debate concerning the NHS provision of certain anti-cancer drugs and the right of individuals to pay to 'top up' their treatment illustrates this dilemma.

A contemporary doctor has to combine individual clinical expertise with the best available evidence as today 'goodness' is defined in terms of competence and performance. ${ }^{8}$ Certainly the current focus of healthcare management is to assess 'goodness' in individuals and healthcare systems in terms of measurable data. But this reliance on qualitative and quantitative information does not provide the means to protect society from 'bad' doctors. Consider the case of $\mathrm{Dr}$ Harold Shipman; although the death rate of
Shipman's patient list turned out to be high when examined retrospectively, this 'bad' doctor was medically skilled and performance outcome measures would give no indication of 'goodness' or 'badness' in such an instance.

Contemporary medical practice has changed almost unrecognisably since Van Gogh painted the portrait of $\mathrm{Dr}$ Gachet in 1890. Life expectancy in the UK has climbed steadily over the past 100 years but the expected time living in poor health is also increasing with a resultant increase in demand for healthcare provision. We are developing new epidemics; obesity, heart disease, alcohol and drug misuse, and diseases associated with the aging process. As preventive medicine pursues ever more risk factors, definitions of disease include more people as patients, which leads to the increasing medicalisation of modern life. In primary care, consultations are becoming more complex as a result of the increasing demands of patients who may have a changing perception of what it means to be well.

Society is changing; we now live in a post-modern, consumerist world. Patient consumerism is endorsed by current political attitudes which support immediate access to health care by the establishment of walk-in centres and the 24-hour telephone advice service NHS Direct. Lord Darzi, the minister in charge of the current review of the NHS is of the view that doctors must treat patients as customers able to shop around for the service they feel most appropriate. Spense $^{9}$ writes:

'One of the most potent forces of irrationality in health care, has been promoted by the government. It has elevated consumer choice - and subjective belief - over medical expertise'.
This results in a society that is strong on rights but short on responsibility leaving a chasm between expectation and reality.

Conditions of employment have changed significantly for GPs as a result of the new GP contract which removed responsibility for the round-the-clock care of patients. The contract was welcomed by the majority of GPs as it allowed them the possibility of achieving an acceptable work-life balance instead of being overwhelmed by the increasing demands of a consumerist society. The new contract's Quality and Outcomes Framework (QOF), based on the achievement of measurable evidencebased 'quality' targets, has also influenced medical practice. Doctors are becoming accustomed to non-medical managers setting measurable outcomes and to receiving payment based on results. There are concerns that as a result, the practice of medicine is changing from being a vocation to a business, reducing GPs' sense of professionalism and diminishing their status in the eyes of the public. Greaves ${ }^{10}$ feels that the role of the GP is being eroded by the imposition of such outcome-based practice but acknowledges that any resistance to this has become increasingly untenable in recent years. As a result, notes Greaves, GPs are 'doing better but feeling worse'. A vast organisation such as the NHS with an annual budget of $£ 18$ billion, $9 \%$ of the total GDP and 1.34 million employees (NHS workforce census) ${ }^{11}$ can never be free of political influence and must be managed. But as Rowan Williams, the current Archbishop of Canterbury, ${ }^{12}$ said:

'It isn't easy to sustain the humane view of medicine (or anything else) when the rules of our humanity are apparently being rewritten to suit the imperatives of management and profit.' 
Hippocrates (460-357 BCE), defined the role of the physician very simply; he 'must have two specific objectives in view with regard to disease, namely to do good or to do no harm'. ${ }^{13}$ The General Medical Council (GMC) defines our contemporary code of conduct in the document, Good Medical Practice, ${ }^{14}$ but is considerably less concise than Hippocrates and not so easy to follow. This document's opening statements are: 'Make the care of your patient your first concern' and 'Protect and promote the health of patients and the public'. The first point advocates a patient-centred approach and the second point requires the doctor to consider the bigger picture; healthcare provision on a larger scale. However these roles are not always compatible as contemporary doctors have access to limited healthcare resources. As the GMC stated in 2003:

'There is a fundamental conflict between population-based public health objectives, which are centrally controlled and with a strong emphasis on cost-effectiveness and equity, and the individual focus of patient care.'. ${ }^{15}$

The practice of evidence-based medicine may seem to offer a safe framework for practice but most decisionmaking in practice is intuitive, requires judgement and involves risk. ${ }^{16}$ Yet, as a consequence of media pressure and an increasingly litigious public, it is becoming almost impossible for doctors to live with uncertainty and this leads to the practice of defensive medicine, 'a desperate euphemism for a profound corruption of the patient-doctor relationship' writes Tallis. ${ }^{12}$ He continues:

\section{'The fundamental injunction of Hippocrates - 'first do no harm' - will, since optimal care informed by the intention to do no harm will not necessarily prevent harm from being done, be displaced by one yet more fundamental: 'first cover your ass and damn the harm'.'}

The practice of defensive medicine allows us to abrogate our responsibilities as doctors by giving our own fears priority over those of our patients. 'Good' patientcentred doctors should beware of falling into a defensive trap when their actions are directed by a need to 'cover' themselves in case of any accusations or omissions.

Society has a high expectation of the 'goodness' or inherent virtue of doctors and this is apparent in the shock and horror felt when doctors fall from this standard. The atrocities of Harold Shipman were so beyond the comprehension of both his patients and colleagues that this may have allowed him to continue his actions without detection. The apparent involvement of doctors in terrorist atrocities in London and Glasgow in 2007 was accompanied by widespread disbelief about the actions of men supposed to be committed to saving, not to taking lives. Bewilderment stems not merely from the fact that there can be no more fundamental way of breaking the 'Hippocratic Oath', in which a doctor vows not to act 'with direct intent deliberately to end a human life'; but also because such behaviour defies our expectations.

Trust in doctors has been rocked in recent years by a series of 'scandals' affecting the medical profession which have been widely reported in the media. These include the BSE 'cover up', the Alder Hey organs scandal, the MMR debate and of course the activities of $\mathrm{Dr}$ Harold Shipman. So, what do our patients consider to be the qualities and attributes of a 'good' doctor?

\section{'I remember the time Shipman gave to my Dad. He would come around at the drop of a hat. He was a marvellous GP apart from the fact that he killed my father. ${ }^{17}$}

This quote illustrates that the views of patients may be astoundingly subjective and many attempts to determine the characteristics that the general public consider important in doctors have been inconclusive.

If, as this essay has explored, analysis and surveys, codes of practice, guidelines and protocols cannot define the role of a 'good' doctor then how does the medical profession reconcile the many conflicts presented by the practice of contemporary medicine? A greater understanding of the historical perspective, the sociological influences and a philosophical objectivity may help doctors to adapt to the changing expectations of both the medical profession and society. Accounts from literature and fiction can also help. Traditional literature provides accounts of doctors who battle to be 'good' despite the constraints of society or the limited scope of the health service they are able to provide. Examples include George Eliot's Dr Lydgate in Middlemarch, ${ }^{18}$ and AJ Cronin's Dr Manson in The Citadel..$^{19} \mathrm{~A}$ more contemporary account is found in Robertson Davies' novel The Cunning Man, ${ }^{20}$ a fictional but thought-provoking account of the life and work of a truly humane doctor, whose use of empathy, intuition, and judgement relieved his patients' burdens. Reading such accounts provides the reader with an opportunity to reflect on their own attitudes to issues central to the practice of 'good' medicine.

Let us finish by going back to $\mathrm{Dr}$ Gachet and to consider if he was a 'good' doctor to the artist Van Gogh despite the inescapable fact that his patient committed suicide. In letters to his brother, Van Gogh suggests that Gachet achieved a shared understanding with the artist and gained his respect and trust. I feel it is possible to conclude that the 'good' Dr Gachet provided a degree of consolation to this deeply troubled and depressed man although this did not prevent his suicide. Van Gogh, who wrote that his own art was an attempt to express the terrible passions of humanity has left us with a collection of paintings of the utopia he dreamed of. His images of peaceful tranquility and of simple unpretentious people, including this portrait of Dr Gachet (Page 58), delight us to this day.

\section{Jane Moore}

\section{REFERENCES}

1. Anonymous. Doctors 'most trusted profession'. http://news.bbc.co.uk/1/hi/uk/6105616.stm (accessed 2 Dec 2008).

2. Van Gogh V. Letter from Vincent van Gogh to Wilhelmina van Gogh, Auvers-sur-Oise, c. 12 June 1890 . 
http://www.webexhibits.org/vangogh/letter/21/W23.h tm (accessed 2 Dec 2008)

3. Van Gogh V. Letter from Vincent van Gogh to Théo Van Gogh, Auvers-sur-Oise, c. 10 July 1890

http://www.webexhibits.org/vangogh/letter/21/648.ht $\mathrm{m}$ (accessed 5 Dec 2008).

4. Orme-Smith A, Spicer J. Ethics in general practice: $a$ practical handbook for personal development. Abingdon: Radcliffe Medical Press, 2001

5. Jones R. Declining altruism in medicine. BMJ 2002; 324: 624-625.

6. Berger J, Mohr J. A fortunate man: the story of a country doctor. London: Allen Lane, 1967.

7. Stokes P. 100 essential thinkers. London: Arcturus Publishing Ltd, 2002.

8. Hurwitz B, Vass A. What's a good doctor, and how can you make one? BMJ 2002; 325: 667-668.

9. Spence D. Not sick, just low. BMJ 2007; 334: 1116.

10. Greaves D. The healing tradition: reviving the soul of western medicine. Abingdon: Radcliffe, 2004.

11. NHS staff numbers. NHS, 2008 .

http://www.ic.nhs.uk/statistics-and-datacollections/workforce/nhs-staff-numbers (accessed 5 Dec 2008).

12. Tallis R. Hippocratic oaths. London: Atlantic Books, 2004.

13. Hippocrates. Epidemics-Book 1, Section XI. In: Adams F (trans.). The genuine works of Hippocrates. Baltimore: William \& Wilkins Co, 1939.

14. General Medical Council. Good medical practice. http://www.gmc uk.org/guidance/good_medical_practice/index.asp (accessed 2 Dec 2008)

15. General Medical Council. Tomorrow's doctors: recommendations on undergraduate education. London: GMC, 2003

16. Greenhalgh T. Intuition and evidence - uneasy bedfellows? Br J Gen Pract 2002; 52: 395-400.

17. Rudol C. In: Barkham P. The Shipman Report. Times 2002; July 20: 15 .

18. George E. Middlemarch. London: Penguin Modern Classics, 1994.

19. Cronin AJ. The Citadel. Sevenoaks: New English Library, 1983.

20. Davies R. The Cunning Man. London: Penguin Books, 1994.

DOI: 10.3399/bjgp09X394950

\section{Maike Fitzpatrick}

\section{The lessons of Baby $\mathbf{P}$}

Although the case of Baby P, killed at the age of 17 months by his mother, her boyfriend and a lodger has provoked a national controversy, for me it is very close to home. I live near to where Baby $\mathrm{P}$ lived in the London borough of Haringey, whose officers have been held to blame, and I have long been involved in child protection work as a GP in the neighbouring borough of Hackney.

My immediate feelings of horror and outrage at the savage abuse suffered by Baby $P$ and sympathies for his wider family, were soon followed by concerns for the doctors and other professionals involved, and the familiar sentiment of 'there but for the grace of God ...'. These concerns were particularly reinforced by vivid memories of a case with many similarities in our practice more than a decade ago.

In this case a baby of a similar age to Baby $\mathrm{P}$ was killed by his mother's boyfriend. The peculiar intimacy of the fatal blow - inflicted by head-butting expressed both the ferocity and the barbarity of the assault, in a way strikingly similar to the account of Baby P's fractured spine and multiple injuries. The man who was convicted in our case (of previous good character and sound mental health) later conceded that he knew from the moment he met this baby he was destined to kill him. As Andrew Cooper, professor of social work at the Tavistock, observes in a thoughtful commentary, 'the treatment of Baby $P$ reminds us that there are people whose minds, actions, motives, and ways of relating to others seem incomprehensible'. ' $\mathrm{He}$ also notes that research into serious case reviews of children killed or injured between 2003 and 2005 revealed that nearly $90 \%$ of the most dangerous cases were not on the child protection register. He counsels against concluding from such cases that the system is failing, because 'arguably', it was 'never designed to deal with these extremes of human behaviour'.

The inquiry into our case came to the same banal conclusions as every other such inquiry over several decades: everybody was to blame, there was a lack of inter-agency coordination and everybody should try harder in future. In fact, as I observed in a response to the official report, the inquiry confirmed that, even though approved procedures had been followed to the letter, it was clear that nobody could have anticipated and prevented what happened. The striking difference from the Baby $\mathrm{P}$ case reflecting the highly arbritrary and irrational character of the recent furore was that this one attracted little local publicity and no national interest. Hence it was not followed by the sort of witchhunting and political posturing that has accompanied the recent case, leading to numerous sackings and resignations in Haringey.

The vituperative media response to the death of Baby $P$ reveals popular prejudices against people who live in relatively deprived inner-city areas and an inability to acknowledge the extremes of depravity of which human beings are capable. The scapegoating of the social workers and other professionals reflects the need to find somebody to blame and the wishful thinking that all cases of extreme cruelty to children can be prevented. It also serves to justify the extension of professional intervention into all aspects of child development in ways that will not improve protection against abuse but may further undermine parental confidence and family cohesion. ${ }^{2}$

'Think dirty' is the prevailing advice to doctors and health visitors and others who are in day-to-day contact with young children and their families. Inflated estimates of the prevalence of child abuse encourage suspicion and mistrust between professionals and parents. ${ }^{3}$ But working on the presumption that every child who comes into the surgery may be at risk of becoming another Baby $\mathrm{P}$ is not conducive to good relations with parents, or, ultimately, to the interests of children.

\section{REFERENCES}

1. Cooper A. Misguided vengeance. http://www.guardian.co.uk/commentisfree/2008/ dec/02/baby-p-haringey-social-services-sackings (accessed 5 Dec 2008)

2. Furedi F. Why moral opportunists are exploiting this tragedy. Spiked-online, 2008.

http://www.spiked-

online.com/index.php?/site/article/5935/ (accessed 5 Dec 2008)

3. The Lancet, UCL Institute of Child Health, $\mathrm{RCPCH}$. Child maltreatment. http://www.lancet.com/series/child-maltreatment (accessed 8 Dec 2008).

DOI: 10.3399/bjgp09X394969 